\title{
Correction to: Where Have Personnel Policies on Early English Language Learning Taken Us in Mexico So Far?
}

\author{
Laura García-Landa
}

\section{Correction to:}

Chapter 10 in: S. Zein, M. R. Coady (eds.), Early Language

Learning Policy in the 21st Century, Language Policy 26, https://doi.org/10.1007/978-3-030-76251-3_10

The book was inadvertently published with incorrect last name of the author. The last name of the author has now been corrected in the chapter 10 .

The updated version of the chapter can be found at https://doi.org/10.1007/978-3-030-76251-3_10 